\title{
Can music improve the symptoms of stable angina? A randomized controlled trial ${ }^{*}$
}

\author{
Samitha Siritunga ${ }^{1 \#}$, Kumudu Wijewardena $^{2}$, Ruwan Ekanayaka ${ }^{3}$, Premadasa Mudunkotuwa $^{4}$ \\ ${ }^{1}$ National Institute of Health Sciences, Kalutara, Sri Lanka; \\ ${ }^{\#}$ Corresponding author: sssiritunga@yahoo.com \\ ${ }^{2}$ Department of Community Medicine, Faculty of Medical Sciences, University of Sri Jayawardhanapura, Nugegoda, Sri Lanka \\ ${ }^{3}$ Institute of Cardiology, National Hospital, Colombo, Sri Lanka \\ ${ }^{4}$ Department of Languages and Cultural Studies, University of Sri Jayawardhanapura, Nugegoda, Sri Lanka
}

Received 4 January 2013; revised 3 February 2013; accepted 5 March 2013

Copyright (C) 2013 Samitha Siritunga et al. This is an open access article distributed under the Creative Commons Attribution License, which permits unrestricted use, distribution, and reproduction in any medium, provided the original work is properly cited.

\begin{abstract}
Worldwide, the leading cause of death is ischemic heart disease. Other than medical and surgical management, alternative therapy such as relaxing music has been identified as having an impact on reducing morbidity in ischemic heart disease. Although several studies have been conducted to find out the impact of music on pain, anxiety, heart rate and stress in myocardial ischaemia, literature on the long term impact of music on severity of symptoms associated with stable angina is very sparse. Therefore, the whole purpose of this study was to determine the long term effects of Indian music on severity of symptoms in patients with stable angina. Methodology: A single blind randomized clinical trial was conducted on 60 patients of 45 to 65 years of age with stable angina. Intervention group $(n=30)$ listened to a music based on Indian classical system at home twice a day complementary to their regular treatment for a period of one month. Control group $(n=30)$ was only on their usual treatment. Both groups were assessed prior and one month after the study period for severity of symptoms based on Canadian classification of angina guidelines and their treatment. Results: Severities of symptoms (timing of the chest pain, chest pain during walking and climbing a staircase, the effect of chest pain in day to day physical activities, frequency and the number of GTN used per week and frequency of consultation a doctor for chest pain)
\end{abstract}

*Competing interests: The authors declare that they have no competing interests. were significantly improved in the study group $(p<0.05, p<0.01)$ after intervention. However, the control group did not show any significant changes $(p>0.05)$. Conclusion: Systematically, regular listening of music based on Indian classical system significantly improves the severity of the stable angina symptoms. Hence music has a potential benefit in considering for use as complementary to angina treatment in reducing morbidity.

Keywords: Music; Indian Classical; Stable Angina; Canadian Classification of Angina; GTN;

Complementary; Symptoms; Severity

\section{BACKGROUND}

Angina pectoris, usually known as angina, is the chest pain due to ischemia of the heart muscle and obstruction or spasm of the coronary arteries. The main cause of angina is atherosclerosis of the coronary arteries. Angina can commonly be classified according to the severity of the symptoms. The most commonly used classification is the Canadian Cardiovascular Society classification (Canadian Classification of Angina-CCA) (Table 1) [1] in which Class 1 is the least severe status while class 4 is the most severe status [1].

Management options include lifestyle modification, drug treatment and revascularization [2]. In addition, relaxation techniques such as music therapy, meditation aimed at reducing stress and anxiety are also considered [3].

The aim of management is to stop or minimize symptoms, and to improve quality of life and long-term morbidity and mortality. According to world health organi- 
Table 1. Canadian Cardiovascular Society classification system of Angina.

\begin{tabular}{cc}
\hline Ordinary physical activity such as walking, \\
climbing stairs etc. does not cause angina. \\
Angina occurs with strenuous, rapid or \\
prolonged exertion at work or in recreation. \\
Slight limitation of ordinary activity. \\
Angina occurs on walking or climbing \\
stairs rapidly walking uphill or walking or \\
climbing stairs after meals or in cold, in \\
wind, under emotional stress or only \\
during the first few hours after wakening. \\
Angina occurs on walking several hundreds \\
yards on the level and climbing more than \\
one flight of ordinary stairs at a normal \\
pace and in normal conditions. \\
Marked limitation of ordinary physical \\
activity. Angina occurs on walking \\
one to two hundred yards on the level \\
and climbing one flight of stairs in \\
normal conditions and at a normal pace. \\
Class $3 \quad$ mability to carry on any physical activity \\
without discomfort. Anginal symptoms \\
may be present while resting.
\end{tabular}$\quad$ Most severe

zation global status report on non-communicable disease 2010 [4], in 2008, 63\% deaths in the world were due to non-communicable diseases comprising mainly cardiovascular diseases, cancers, diabetes and chronic lung diseases. In 2008, nearly $80 \%$ (29 million) deaths due to non-communicable diseases occurred in low- and middle-income countries. Therefore, in most countries, health related cost of Cardio vascular diseases (CVD) accounts a larger proportion of the health budget and it will be the leading health related problem which will cost the largest proportion of the health budget in future [5-7]. Therefore, the impact on a country's economy by preventing the development of CVD and also minimizing the associated morbidity and mortality is immense.

\section{Ischaemic Heart Disease and Music Therapy}

Music therapy uses music to promote healing and to enhance the quality of life and it is often used and prescribed in the management of stress [8]. It is a complementary therapy that is used along with other treatments to help patients cope mentally and physically with their diagnosis [9]. Music improvisation, receptive music listening, song writing, lyric discussion, imagery and relaxation and performance of music are among different approaches of music therapy [10].

Effect of relaxing music has been thought to be due to complex neurophysiological phenomenon which affects entire nervous system and the stress hormones [11]. With theses mechanisms, it reduces the rate of formation of the atheromatous plaque, the metabolic rate, heart rate, blood pressure, free fatty acids and oxygen consumption and thereby reduces the severity of the disease [12, 13]. Additionally, relieving pain through endorphins secreted from the pituitary gland would enhance the disease related quality of life.

Practicing music therapy is easy; prior preparations are not necessarily needed; it can be practiced at any given time. In general, it is relatively inexpensive [14] and considerably safe [15].

Though the effect of Indian and western relaxation music on physical health has been identified since the ancient period $[11,12,16]$, no published studies are from Sri Lanka. Moreover, researches done on Indian classical music were sparse. Most of the studies conducted elsewhere in patients with myocardial infarction (MI) have focussed on determining short term effects of music such as on stress, anxiety, blood pressure and heart rate at different setups [3,17-20]. The results varied from study to study. While some were able to show a significant effect of music on heart rate variability, blood pressure, pain, anxiety and rapid recovery $[3,19,20]$, some were not able to show a significant impact of music $[17,19]$. The effect of frequent listening to music for a longer period on symptoms associated with IHD has not been studied. Assessing the effect of music on associated symptoms is important because symptoms are generally perceived by people as a measure of their health and there by the quality of life. In addition, it indirectly assesses the severity as well as the progression of the disease; hence the underlying pathophysiology.

Therefore, the aim of this study was to determine the long term effects of frequent listening to Indian classical music on severity of symptoms in chronic stable angina (SA) patients.

\section{METHODOLOGY (Figure 1)}

This was a hospital based single blind randomised intervention study. The estimated sample size was 60 calculated for the effect size of $20 \%$ from the base line of the time taken to $1 \mathrm{~mm}$ ST segment depression in exercise ECG at $\alpha=0.05$ and power at $0.8(80 \%)$.

Both male and female patients between of 45 to 65 years of age with clinically diagnosed chronic stable angina confirmed by exercise ECG using Bruce protocol were selected as the sample. Patients who had any other heart diseases or any other chronic medical or psychological illness and whose clinical condition was not stable which would require frequent change of the treatment were excluded. We recruited 30 patients each to intervention (study) and control groups by restricted randomisation technique after obtaining the informed written consent. 


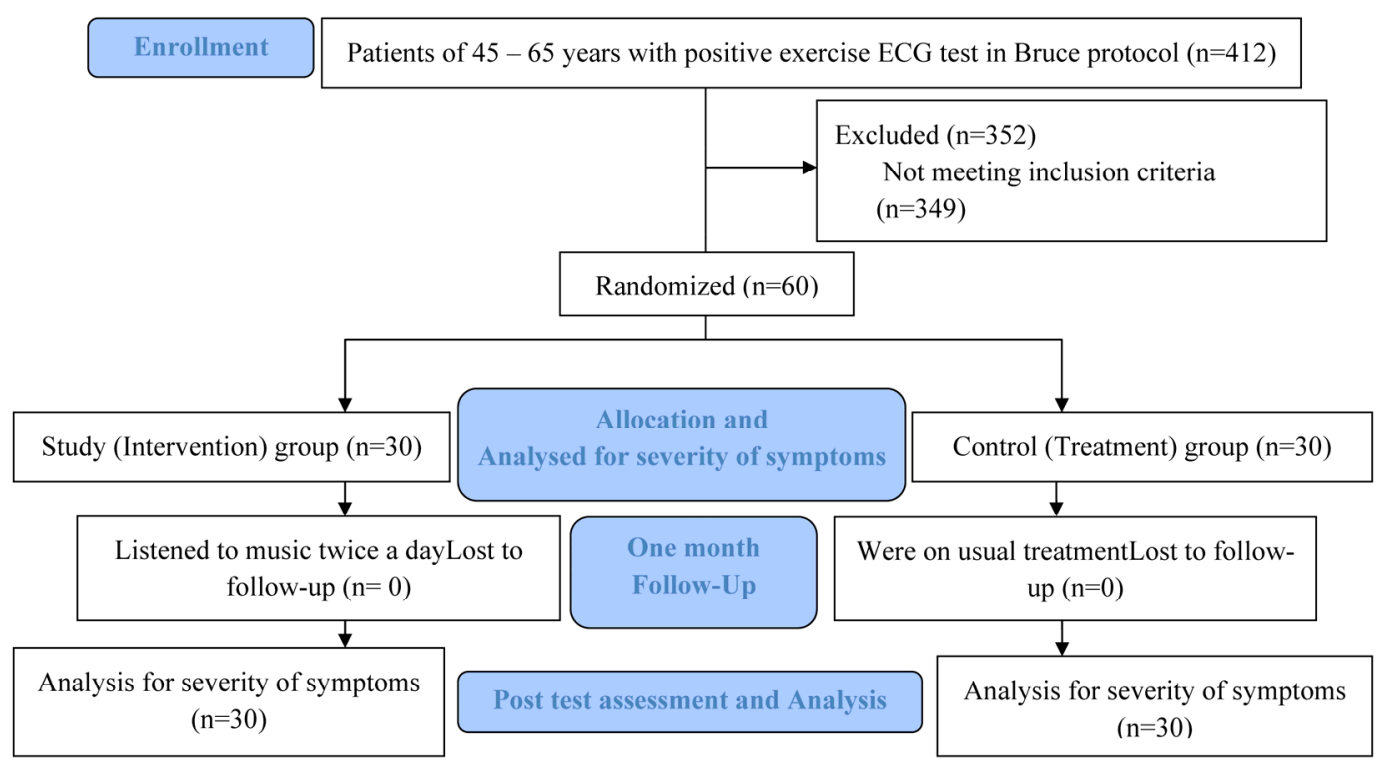

Figure 1. Methodology.

\subsection{Data Collection}

The intervention period was one month. Data was obtained from the participants at the time of recruitment for the study (Pre test) and after the completion of intervention period (Post test). Severity of the symptoms was assessed according to the CCA guidelines and details treatment obtained for chest pain using a pre tested, self administered questionnaire. Based on the CCA guidelines, timing of the chest pain, the chest pain during walking and climbing a stair case and the effect of chest pain in day to day physical activities during month before the pre test and during the one month period of intervention were assessed. Additionally, frequency and the number of Glyceryl Trinitrate (GTN) used duringone week before data collections and the frequency of consultation a doctor for chest pain during one month period before the pre and post test assessments were also measured.

\subsection{Intervention}

The intervention group was provided an audio compact disc (CD)which lasts about 22 minutes with a music based on Indian classical Rag Darbari Kanada which had been identified as having effective for cardio vascular system with empirical studies [21] to listen till the end of the track complementary to their usual medicines for a period of one month. Patients were instructed to listen to music twice a day preferably early in the morning and in the evening using either ear phones or head phones. Special measures were taken to ensure the compliance of the study individuals. During the whole period of one month, the control group was kept only on their usual medicines.

The significant level of a statistical test was considered as 0.01 and 0.05. Significance obtained from the statistical tests $\leq 0.01$ were all considered as 0.01 . To analyse the data, 2 sample proportions and non parametric tests such as Mann Whitney $U$ test and Wilcoxon Signed ranks test were applied where relevant.

The approval of ethics review committee of University of Sri Jayawardhanapura, Sri Lanka was obtained before commencing the study.

\section{RESULTS AND DISCUSSION}

All the patients who had been selected for the study attended for the post test assessment with $0 \%$ loss to follow up.

\subsection{Base Line Characteristics}

Both groups were approximately similar in the measured socio demographic variables (Table 2). Female to male ratio in intervention and control groups were 1:5 and 1:3.3 respectively. About $63 \%$ were between 45 to 55 years and almost all were Sinhalese. Majority were Buddhist in religion. Almost all were married except 1 in the study group. Each participant had either primary or secondary level education. Though majority indicated that they were neither current smokers nor current alcohol drinkers, about $40 \%$ and $30 \%$ were social drinkers of alcohol in study and control group respecttively.

12 participants from each group were on treatment for less than 1 year while rest were on treatment for more than 1 year. Both groups were almost similar in current 
drug treatment for the heart disease.

\subsection{Individual Preference of Music and Practicing a Kind of Relaxation Techniques}

While all the participants were fond of music, they all have indicated the need for relaxing music complementary to their current medication. But only about $45 \%$ of the study group and $30 \%$ of the control group indicated that they were practicing any kind of mind relaxation technique.

\subsection{Influence of Intervention on Severity of the Disease}

Both groups were similar in severity of the diseases measured according to CCA and treatment before the intervention $(p>0.05)$. But after the intervention, except for the development of chest pain during climbing a stair case ( $p>0.05)$, both groups were significantly different for the severity of angina $(p<0.05$ and $p<0.01)$.

When compared the pre and post test results, after one month of intervention, except for the distance could walk without chest pain $(p>0.05)$, intervention group has shown a significant difference in all other aspects meas- ured in the severity $(\mathrm{p}<0.05$ and $\mathrm{p}<0.01)$ and in the treatment $(\mathrm{p}<0.01)$ (Tables 3 and 4). The intervention group has significantly improved from more severe classes to less severe classes according to CCA which were more in favour of better prognosis compared to the control group after intervention.

According to the results of our study, the rate of improvement of the severity of the symptoms associated with stable angina significantly improved with regular, systematic listening of music complementary to usual medical management. Even though no similar study found to have conducted earlier, observed results of our study support the results obtained by previous studies conducted to find out the effect of music on heart rate, anxiety and pain in heart disease patients at various settings such as acute care setting, during cardiac catheterization and coronary angiogram $[3,19,20]$. But the effect observed in the current study was more prolonged and persistent. Moreover, our study did not show any adverse effect due to music listening for a prolonged period. This also confirms the current evidence of safety of relaxation music in therapeutic use [15]. Moreover, this study also showed similar improvement in angina symptoms with music listening which has been observed with anti anginal treatment $[22,23]$.

Table 2. Baseline characteristics.

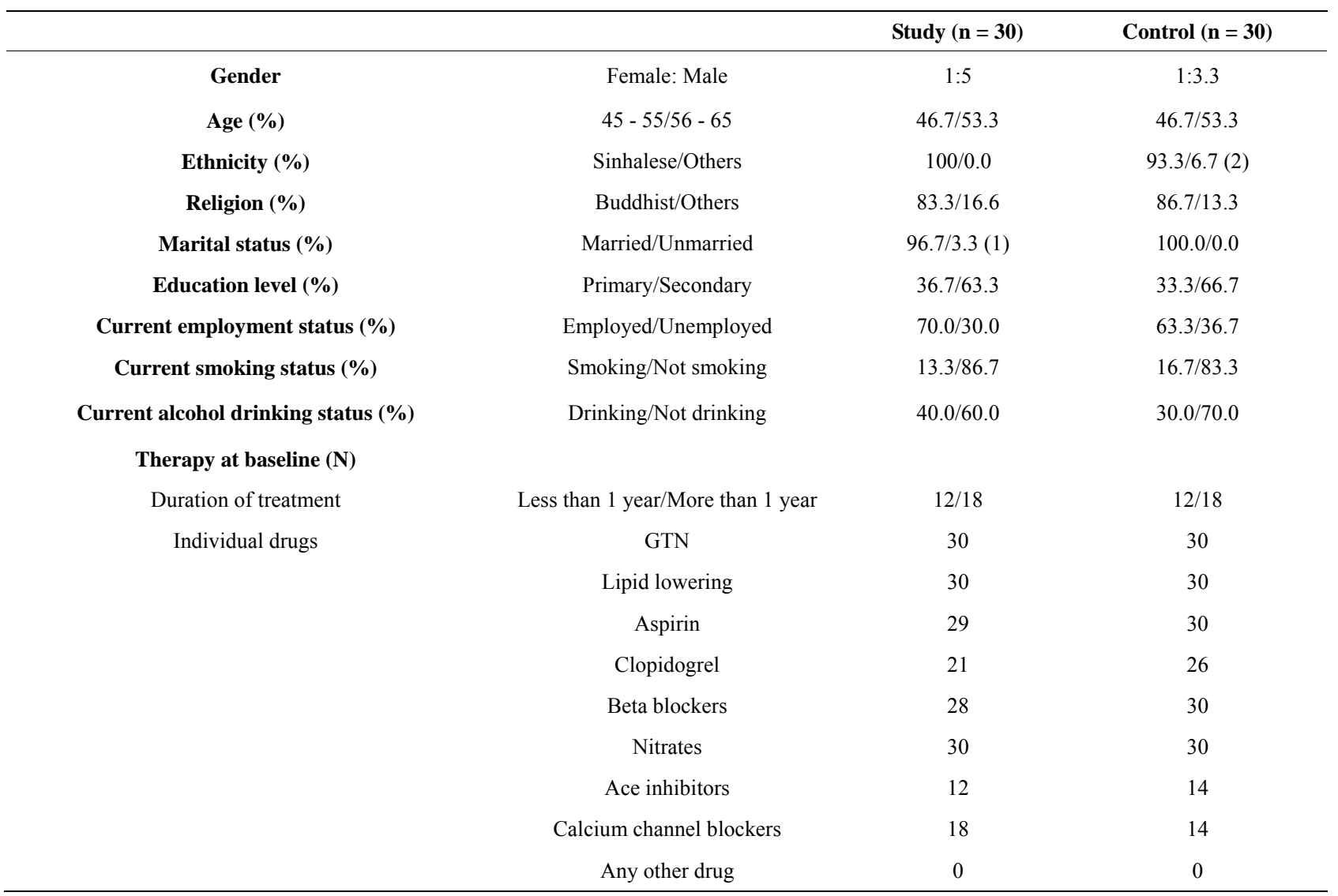


Table 3. Influence of music on different situations of development of chest pain.

\begin{tabular}{|c|c|c|c|c|}
\hline \multirow{2}{*}{ Variable measured } & \multicolumn{2}{|c|}{$\begin{array}{c}\text { Study }(n=30) \text { Pre test and } \\
\text { post test }\end{array}$} & \multicolumn{2}{|c|}{$\begin{array}{l}\text { Control }(n=30) \text { Pre test } \\
\text { and post test }\end{array}$} \\
\hline & $\mathbf{Z}$ & $\mathbf{p}$ & $\mathbf{Z}$ & $\mathbf{p}$ \\
\hline Timing of chest pain & $2.4^{*}$ & $<0.05$ & $1.5^{*}$ & $>0.05$ \\
\hline chest pain during first few hours after wakening & $2.1^{*}$ & $<0.05$ & $0.7^{*}$ & $>0.05$ \\
\hline Chest pain during walking & $4.6^{*}$ & $<0.01$ & $0.4^{*}$ & $>0.05$ \\
\hline Distance could walk till the development of chest pain (of those who had pain) & $1.7^{*}$ & $>0.05$ & $0.9^{*}$ & $>0.05$ \\
\hline Chest pain during climbing a stair case & $3.3^{*}$ & $<0.01$ & $1.2^{*}$ & $>0.05$ \\
\hline Number of stairs could climb until development of chest pain (of those who had pain) & $2.2^{*}$ & $<0.05$ & $2.1^{*}$ & $<0.05$ \\
\hline The effect of chest pain on day to day physical activities of the patients & $4.2^{* *}$ & $<0.01$ & $2.1^{* *}$ & $<0.0$ \\
\hline
\end{tabular}

*2 sample proportion; ${ }^{* *}$ Wilcoxon Signed rank test.

Table 4. Influence of intervention on treatment for chest pain.

\begin{tabular}{|c|c|c|c|c|}
\hline \multirow{2}{*}{ Variable measured } & \multicolumn{2}{|c|}{$\begin{array}{c}\text { Study }(n=30) \text { Pre test and } \\
\text { post test }\end{array}$} & \multicolumn{2}{|c|}{$\begin{array}{c}\text { Control }(n=30) \text { Pre test and } \\
\text { post test }\end{array}$} \\
\hline & $\mathbf{Z}$ & $\mathbf{p}$ & $\mathbf{Z}$ & $\mathbf{p}$ \\
\hline Whether sub lingual GTN used or not during last week & $4.2^{*}$ & $<0.01$ & $1.3^{*}$ & $>0.05$ \\
\hline Frequency of using sub lingual GTN during last week & $2.9^{* *}$ & $<0.01$ & $1.3^{* *}$ & $>0.05$ \\
\hline Number of GTN used during last week & $3.4^{* *}$ & $<0.01$ & $1.2^{* *}$ & $>0.05$ \\
\hline No of visits to a medical officer for the treatment of chest pain & $3.1^{* *}$ & $<0.01$ & $1.1^{* *}$ & $>0.05$ \\
\hline
\end{tabular}

*2 sample proportion; ${ }^{* *}$ Wilcoxon Signed rank test.

In addition, it shows the implications of music on severity of the symptoms which indirectly indicates its effect on the underlying pathophysiology of myocardial ischaemia. The dramatic improvement observed would further help to understand the pathophysiological phenomenon of the effect of relaxing music. Furthermore, it would help to presume newer theories for explaining the effect of music such as metabolic shifting which is postulated by scientists in order to find out newer therapies for the treatment of IHD $[24,25]$.

A study if able to be conducted for a longer time in a larger cohort will show feasibility and acceptability of music as complementary treatment and the effect of it on cardiac morbidity. Therefore, our study warrants further investigation in definitive, large-scale, randomized clinical trials.

\section{CONCLUSION}

Complementary listening to the music based on Indian Classical system twice a day for one month period significantly improved the severity of the symptoms of stable angina patients aged between 45 and 65 years measured according to the CCA guidelines and the treatment for chest pain. But a similar improvement in the severity did not observed in the control groups who were only on prescribed medicines. Therefore, listening to music could be considered as a complementary to regular treatment for SA. Additionally, as listening to relaxing music would be easier and cost effective, it would help to minimise cost to the state by reducing morbidity in SA patients.

\section{ACKNOWLEDGEMENTS}

We thank Professor R. Sooriarachchi, Deptartment of Statistics, University of Colombo, Sri Lanka for the assistance and guidance given in the calculation of the sample sizes for the study, the National Health Research Council, Sri Lanka for supporting financially a part of this study and for giving technical guidance, director of National Hospital, Sri Lanka, head and the staff of Coronary Care Institute, National Hospital, Sri Lanka for giving necessary facilities to conduct the study and all participants of the study for the support given to conduct it.

\section{REFERENCES}

[1] Walsh, M.J., Shelley, E. and Murphy, R.T. (2003) Clinician's guide to angina. Arnold, London.

[2] National Clinical Guidence Centre (2011) Management of stable angina. NICE clinical guidance. In: N.C.G. Centre, Ed., CG 126, National Institute for Health and Clinical Excellence, UK.

[3] White, J. (1999) Effects of relaxing music on cardiac autonomic balance and anxiety after acute myocardial in- 
farction. American Journal of Critical Care, 8, 220-230.

[4] WHO (2011) Global status report on noncommunicable diseases 2010. In: A. Alwan, Ed., Global Status Report on Noncommunicable Diseases 2010. WHO, Geneva, 2011.

[5] Fernández, R.L., et al. (2006) Cost of cardiovascular diseases in the United Kingdom. BMJ Heart, 92, 1384-1389. doi:10.1136/hrt.2005.072173

[6] Liu, J.L.Y., et al. (2002) The economic burden of coronary heart disease in the UK. BMJ Heart, 88, 597-603. doi:10.1136/heart.88.6.597

[7] Ministry of Healthcare Nutrition and Uva-Wellassa Development (2005) Economy and health; taking Sri Lanka towards the global best. Ministry of Healthcare, Nutrition and Uva-Wellassa Development, Colombo.

[8] ICBS Inc. (2007) Stress the silent killer. http://holisticonline.com/stress/stress home.htm

[9] Yale Medical Group (2005) Alternative therapy-Art therapy, dance therapy, music therapy, and imagery. http://www.yalemedicalgroup.org/stw/Page.asp?PageID= STW025835

[10] Yale Medical Group (2006) Alternative therapy-Art therapy, dance therapy, music therapy, and imagery. http://www.yalemedicalgroup.org/stw/Page.asp?PageID= $\underline{\text { STW025835 }}$

[11] Jyothi, A. (2004) Healing by music therapy-ragas. http://akhandjyoti.org

[12] Chiu, P. and Kumar, A. (2003) Music therapy: Loud noise or soothing notes? International Paediatrics, 18, 204208.

[13] Kumar, P. and M. Clerk (2001) Clinincal medicine: A textbook for medical students and doctors. 4th Edition, W. B. Saunders, Edinburgh.

[14] Iriarte Roteta, A. (2003) Music therapy effectiveness to decrease anxiety in mechanically ventilated patients. Enfermeria Intensiva, 14, 43-48.

[15] American cancer Society (2010) Music therapy. Find support and treatment. http://www.cancer.org/Treatment/TreatmentsandSideEffe
cts/ComplementaryandAlternativeMedicine/MindBodyan dSpirit/music-therapy

[16] Sarim, T.V. (2002) Healing with music. http://www.the-south-asian.com

[17] Bally, K. (2003) Effects of patient controlled music therapy during coronary angiography on procedural pain and anxiety distress syndrome: A clinical article. Critical Care Nurse, 23, 50-57.

[18] Bradt, J. and Dileo, C. (2009) Music for stress and anxiety reduction in coronary heart disease patients. Cochrane Database of Systematic Reviews, Article ID: CD006577.

[19] Elliott, D. (1994) The effects of music and muscle relaxation on patient anxiety in a coronary care unit. Heart \& Lung, 23, 27-35.

[20] Guzzetta, C.E. (1989) Effects of relaxation and music therapy on patients in a coronary care unit with presumptive acute myocardial infarction. Heart \& Lung, 18, 609. 616.

[21] Mudunkotuwa, P. (2006) Music therapy. In: Siritunga T.L.S.S., Ed., Bhathkhande Sangeeth Vidyapith, Sri Lanka.

[22] Bonetti, P.O., et al. (2005) Long-term benefits and limitations of combined antianginal drug therapy in elderly patients with symptomatic chronic coronary artery disease. Journal of Cardiovascular Pharmacology and Therapeutics, 10, 29-37. doi: $10.1177 / 107424840501000104$

[23] Lad, T.S., et al. (2008) Effect of ivabradine, a novel antianginal agent, on heart rate and symptom control: A first experience in a clinical "real-world" setting. British Journal of Cardiology, 1, 106-109.

[24] Szwed, H. (2000) The place of metabolic treatment: Metabolic approach in heart failure. American Heart Journal, 139, 5120-5123.

[25] O'Meara, E. and McMurray, J.J.V. (2005) Myocardial metabolic manipulation: A new therapeutic approach in heart failure? Heart \& Lung, 91, 131-132.

\section{LIST OF ABBREVIATIONS}

CVD: Cardio Vascular Diseases;

IHD: Ischaemic Heart Disease;

CCA: Canadian Classification of Angina;

MI: Myocardial Infarction;

SA: Stable Angina;

GTN: Glyceryl Trinitrate;

CD: Compact Disc. 